\title{
DESIGNING A MODEL OF MEDICAL EQUIPMENT PURCHASE MANAGEMENT IN HOSPITALS OF TEHRAN UNIVERSITY OF MEDICAL SCIENCES
}

\author{
Azam Lari, Ali Komeili, Kamran Hajinabi, Leila Riahi \\ Department of Health Services Administration, Science and Research Branch, Islamic Azad University, Tehran, Iran.
}

Correspondence: hajinabi@srbiau.ac.ir

\begin{abstract}
OBJECTIVE:

Medical equipment plays an effective and vital role in the diagnosis and treatment of diseases. Each society dedicates a plethora of health resources to these facilities. Since prioritizing and resource allocation are crucial in low-income countries with limited health resources, understanding and improving the purchase management of medical equipment in hospitals is a primary key for preparing high -quality health services. The aim of this study was to design a model for medical equipment purchase management at hospitals affiliated with the Tehran University of Medical Sciences.
\end{abstract}

METHODS:

The statistical population for the present applied study, consisted of 623 people and the research sample was comprised of 420 people, which was selected using the stratified random sampling method. Data was collected using a researchermade questionnaire whose variables were extracted from comparative studies and whose validity was measured by the relative content validity coefficient, content validity index and Cronbach's alpha coefficient. The SPSS 18 and AMOS were employed for analyses.

RESULTS:

The most and the least effective aspects of medical equipment purchase management in the studied hospitals were found to be decision-making (path coefficient of 1.244) and organization respectively (path coefficient of 0.845 ).

\section{CONCLUSION:}

It is crucial to take factors into consideration when using the facilities and capacities available in health and treatment centres. The proposed model can best guide buyer institutions to move towards efficient purchase mentioned in upstream policy documents.

\section{KEYWORDS}

Purchase Management; Medical Equipment; Hospital

\section{INTRODUCTION}

Today's rapid and continuous technological evolution, which affects most production sectors, also involves healthcare. Indeed, healthcare technologies have become an essential part of the provided services, as they play increasingly significant roles in the diagnosis and treatment of patients. [1,2] The equipment represents a 
very dynamic and rapid group of health technology innovations, which annually was allocated a large proportion of health and treatment resources to the purchase, repair, maintenance, and replacement of such equipment both inside and outside country. [3] The growing number of equipment is making a significant contribution to the mounting healthcare costs making it contradict the emphasis of making healthcare affordable. [4] Stewart reported that the number of medical equipment increased by $62 \%$ over the past 15 years while the average utilization rate of mobile equipment is only 42\%; thus, increasing hospital's acquisition budgets and maintenance cost. [5] According to surveys conducted by Ably, the annual growth rate of these costs is increasing by $15 \%$ to $20 \%$, accounting for about $45 \%$ of the operating budget of hospitals $[6,7]$, in which the costs of medical equipment play a significant role in the health expenditure growth. [8]

Due to the fact that health centres are usually faced with constrained resources that must be distributed carefully, policymakers across high _and middle _ income countries have grown interested in the role that accurate purchasing could theoretically have in optimizing the cost-effective provision of healthcare services while simultaneously maximizing population health. [9-10] On the other hand, given the growing wave of expectations in updating equipment and technologies in the last decade, it seems that now is the time to consider purchase management of medical equipment in today's world economic conditions. Purchase management of medical equipment has a critical and important role; with clearly defined Purchase management organizations can explain to their employees what purchasing is and how it should be conducted in that specific organization. It also helps employees to quickly grasp the main purchasing processes and activities and can be used for problem-solving and decision-making. [10, 11]. It is facing a growing pressure to provide visibility and traceability of the purchase, to reduce fraud, to improve flexibility and to ensure communication between everyone involved.

The complexity of the technological assets and medical equipment found in healthcare facilities, in terms of number and diversity, is reflected in the complexity of purchase management, which must be efficient so that the equipment can always be used safely and appropriately. Therefore, Due to lack of funding, health care managers struggle to maintain a balance between patients' access to modern health services and the economic stability of these centres; they also try to select and buy the most costeffective medical equipment which ultimately affects the development of every country on a national level. [12-14] the uncertainty that comes with purchasing medical equipment make it especially important to select management that can manage the limited organizational resources effectively; these decisions must be made in the changing environment of health policies; patients' demands and hospital competition with other medical centres. [15 -18]

Management policies on the efficient hospital purchases of medical equipment are key to providing high-quality health services. [19-21] this paper reviews the studies conducted on hospital management around the world and presents a well-organized and systematic effort to make fundamental decisions in the field of medical equipment purchase management.

\section{METHODS}

This descriptive-analytical, cross-sectional and applied study was carried out in 2018 at hospitals affiliated with Tehran University of Medical Sciences. It was conducted in two phases (Figure 1). The first phase consisted of a library study and a literature review. Data was collected from a series of references including databases, reference books, published reports and information banks such as Medline, PubMed, and other sites related to the Ministry of Health and other authorities including governmental and nongovernmental organizations, documents from the Medical Equipment Department of the Ministry of Health, treatment and medical education, documents from the medical equipment offices of Iran Universities of Medical and theses available at the National Library, Tehran University of Medical Sciences and Islamic Azad University (Science and Research Unit) (2006-2017). Comparative tables were used to analyze the collected data.

Comparative tables were used to analyze the collected data. Making use of similarity and difference points shown in the comparative table, 66 variables were identified. The variables were weighted using the Shannon entropy method. Experts were then asked to assign appropriate weight to each of the necessary indicators, the importance, and the relationship of the known components with the management purchases of medical equipment using the Shannon entropy method. Finally, the 
variables were ranked and 38 variables were finalized with the opinion of experts.

Bagheri et al. In their research said purchase management is a process including decision-making and implementation of written plans to prepare and meet the organization's needs at the right time, with the desired price and quality from reliable and dependable sources according to the capability. The organization's facilities and in the framework of the rules and standards governing the organization know that according to this definition and making use of similarity and difference points shown in the comparative table, and expert comments the research initial model was presented in five dimensions including planning, decision-making, organizing, leadership, and control. [22]

Then, a researcher-made questionnaire was designed according to the initial model and the tools used in studies by Ivelve, Jones, and Tourani. [3, 8,18]

In the second phase of the research, the researcher-made questionnaire along with a schematic outline of the suggested pattern and a description of the model dimensions were given to 20 experts to validate the model. Among the experts were hospital managers, managers and authorities from the Medical Equipment Office of Tehran University of Medical Sciences and the Medical Equipment Unit of the affiliated hospitals; All experts had Ph.D. or M.A. degrees in the fields of either Health and Treatment Service Management or Medical Engineering. The face and content validity of the questionnaire was confirmed in two phases. The first phase was performed using the Delphi method and the second phase was of content type. The Cronbach's alpha coefficient was used to examine the reliability of each studied dimension, first separately and then together. The Likert 5-point scale was used to measure each item on the questionnaire ( 1 = very low, 2 = low, 3 = moderate, 4 = high, and $5=$ very high).

The statistical population of the study consisted of hospital managers, nursing managers, bosses and supervisors of diagnostic and treatment wards and medical equipment units of all hospitals of Tehran University of Medical Sciences as well as managers and experts of medical equipment units of the universities ( $N=623)$. They were selected using the stratified random sampling method. The inclusion criteria were the individuals' organizational posts and their employment in management units, medical units and medical equipment units.
In structural equation modeling methodology, sample size determination is more experimental. Bentler and Chou present a minimum of 5 and a maximum of 10 samples for each parameter. [23] Habibie and Adanvar in their research said the sample size can be determined between 5 and 15 observations per measured variable. [24] In this research, a researcher-made questionnaire has 38 variables. According to experts, 11 views are provided for each variable. Therefore, a total of 420 samples are considered. The number of samples in class was determined according to as follows; hospital managers 35 samples, nursing managers, bosses, and supervisors of diagnostic and treatment wards 352 samples, medical equipment units of all hospitals 26 samples and managers and experts of medical equipment units of the university 7 samples. To complete the sample size (the probability of non-cooperation or omission of incomplete questionnaires), 450 questionnaires were distributed. Finally, 420 completed questionnaires were collected.

\section{FIGURE 1: ARTICLE FLOWCHART}

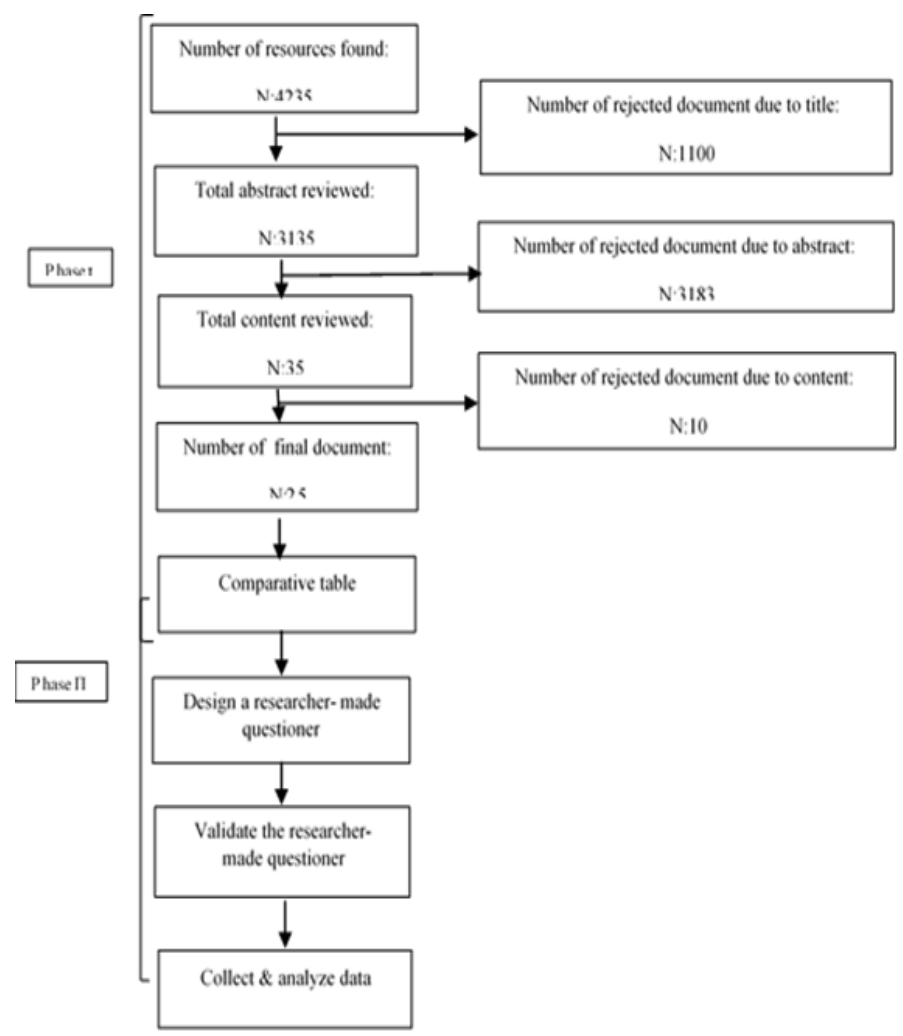

Data was analyzed using descriptive statistics, confirmatory and exploratory factor analysis and SPSS 18 and AMOS. The results provided the suggested purchase management model of hospitals affiliated with Tehran University of Medical Sciences. Ethical considerations in this study included observing ethical principles in the use and dissemination of scientific texts. Moreover, the authors had 
no conflict of interests in the various stages of this research. The samples voluntarily entered the study and were all assured that their questionnaire information would remain confidential. This research is part of a doctoral dissertation entitled "Designing a Purchase Management Model of Capital Equipment and Medical Consumables of Hospitals affiliated with Tehran University of Medical Sciences" and has the code of ethics no. IR.IAU.TMU.REC.1398.042.

\section{RESULTS}

Of the 450 questionnaires distributed, 431 were fully completed and returned. Among which 34 (8\%) were completed by managers and nursing managers, 364 (84\%) were completed by ward supervisors, 26 (6\%) were completed by medical equipment managers and experts of hospitals and 7 (2\%) were completed by medical equipment managers and experts at the university headquarters. 101 (23\%) of the respondents were male, and 330 (77\%) were female. The highest number of respondents was in the age group of $40-50$ years, and the lowest was in the age group of over 50 years. Concerning academic certificates, most respondents had bachelor's degrees and only a few had PhDs or higher. Most respondents had clinical certificates, while a few had studied in the field of management and accounting. Also, most respondents had 20-25 years of service experience, while only a few had 0-5 years of service.

Most of the questions in the measurement model used in this research had the factor load of less than 3 , and most of the fit indices were lower than the standard limit; thus, some questions were deleted to improve the fit index. The results of these modifications (deleting some questions with a low factor load and creating three co-variances between three pairs of errors) improved the model fit index. Table 1 illustrates the mean variance coefficient extracted for the main studied variables and represents the CR> AVE condition in managing the medical capital equipment purchase.

\section{TABLE 1: MEAN VARIANCE COEFFICIENT OF THE MAIN STUDIED VARIABLES}

\begin{tabular}{|c|c|c|c|}
\hline CR>AVE & $\begin{array}{l}\text { COMBINED RELIABILITY } \\
\text { COEFFICIENT (CR) }\end{array}$ & $\begin{array}{c}\text { AVERAGE VARIANCE OF } \\
\text { EXTRACTION (AVE) }\end{array}$ & VARIABLE \\
\hline$\sqrt{ }$ & 0.72 & 0.56 & Planning \\
\hline$\sqrt{ }$ & 0.70 & 0.51 & Decision \\
\hline$\sqrt{ }$ & 0.79 & 0.60 & Organization \\
\hline$\sqrt{ }$ & 0.75 & 0.55 & Leadership \\
\hline$\sqrt{ }$ & 0.79 & 0.68 & Control \\
\hline
\end{tabular}

After examining the measurement model and confirming its indices as well as confirming the construct validity indices, the structural model or the main model was examined in the final step. The same final measurement model was used for this stage, except that the covariances among the endogenous latent variables were deleted and a residual error was left for the endogenous latent variables. The software output showed a suitable fit of the study model (Table 2). After confirmation, the path coefficients and their significance were examined (Table 3, included in appendix 1). In the standard mode, the P-value was significant for all paths.

According to Table 3 in the appendix, "decision making" (path coefficient of 1.244) had the highest impact, while "organizing" (path coefficient of 0.845) had the lowest effect on the purchase management of medical capital equipment. The second most effective aspect was "planning" (path coefficient of 1.238), followed by "leadership and control" (path coefficient of 1.151 and 0.973 respectively). 
TABLE 2: STRUCTURAL AND MEASUREMENT MODEL FIT

\begin{tabular}{lllll}
\hline STRUCTURAL MODEL & MEASUREMENT MODEL & STANDARD RATE & INDEX \\
\hline 1.09 & 1.08 & $3>$ & X2/df \\
\hline 0.017 & 0.016 & $0.08>$ & RMSEA \\
\hline 0.5 & 0.5 & $0.5<$ & PNFI \\
\hline 0.936 & 0.937 & $0.8<$ & GFI \\
\hline 0.922 & 0.922 & $0.8<$ & AGFI \\
\hline 0.474 & 0.5 & $0.9<$ & NFI \\
\hline 0.909 & 0.915 & $0.9<$ & CFI \\
\hline 0.91 & 0.925 & $0.9<$ & IFI \\
\hline 0.407 & 0.41 & $0.9<$ & RFI \\
\hline
\end{tabular}

\section{DISCUSSION AND CONCLUSION}

Due to the increasing use of services in public hospitals, especially hospitals affiliated with Tehran University of Medical Sciences (because most of them are referral hospitals) and since we are currently faced with serious resource constraints, it is crucial to make optimum use of the available facilities. The planned purchase of medical equipment is especially important towards achieving productivity, safety, ease of operation and reduced personnel workload and probable risks.

The findings of the present study showed in the hospitals of Tehran University of Medical Sciences, the decision-making (path coefficient of 1.244) is the most important aspect of purchase management and strongly affects, market and price competitiveness. Owing to the variety of services and products and the hospital's authority to choose products proportional to its needs, understanding the factors influencing decision-making in a competitive environment and using scientific methods to select a product or service in healthcare institutions are of particular importance.

In health centres, evidence suggests that standard medical equipment should be purchased at the lowest prices to increase purchasing power. To achieve this, competitive advantages must be applied and competitive and agreed prices must be taken into consideration. [25-26] The findings of the study of Liyanto et al. also imply that selecting the most reliable supplier in public or private sectors is based on rational purchasing policies and active competition between different providers over quality and price. [25]

Boyer et al. emphasized competitive prices in the Chinese medical equipment market. [27] In a study conducted in India, Blarjan et al. Stated that to avoid high healthcare costs, the Indian government attempted to set a price ceiling for medical equipment. [28] In the present research, respondents paid more attention to the variable "exchange market". Amerion et al. in their research also suggested that price changes often lead to an increase in the cost of the required equipment and parts which would ultimately result in increased maintenance costs. [29] The political atmosphere, sanctions and exchange rate fluctuations in Iran have worsened Iran's access to the medical market and cannot easily be compared with that of the other studied countries.

While the current economic crisis has made industrialized countries of the world wary of using costly technological devices, the application of advanced medical technology is increasing in developing countries, which is associated with wasting enormous economic resources and actual technological power. [30] In this regard, Isaco states that the most important factor causing the waste of resources is purchasing sophisticated equipment, which is underutilized or ignored due to the lack of maintenance and operation specialists. The purchasing of sophisticated equipment often led to about 20 to $40 \%$ in losses. [31] 
A well thought out plan for purchasing medical equipment can help us achieve balance in budgeting different needs. According to studies conducted in many developing countries, the medical equipment substitute plan has led to a significant reduction in normal costs. The traditional method in healthcare centres for purchasing and using new medical equipment is usually based on the physicians whose main concerns revolve around patient health and income. [32] In their research, Pauli and Burns stated that physicians' concerns included the treating of patients and income, so, they often sought to use newer technologies to treat their patients. [33] Boots and other researchers argue that health centres are faced with resource constraints and need to have a realistic analysis for acquiring a new device. [31]

The findings of the study of Saleh et al. imply that if a purchase is made without paying attention to its requirements, the purchased items may fail in meeting actual hospital needs. [30] Ozmir, Kumar, and Chakravaddi et al in their researches stated that rapid technological advances in the Turkish healthcare sector, particularly in recent years, have led to an increase in the use of hightech medical devices, which is mainly due to the government's lack of political commitment to plan and prioritize the purchase of medical equipment. [34-38] While, Mazloum Vajari imply that developing countries such as Iran have limited capital, so it is important to ensure that any investment in medical care technology is made properly. As appropriate management practices create a sustainable environment for medical care technology, strong plans are needed for replacing and purchasing medical equipment. [18]

Concerning leadership, bargain power is useful in many pricing systems to achieve lower agreed prices. In their research, Liyanto and Preker stated that in Canada and Germany, pricing is determined by negotiations between buyers and providers, so the agreed price depends directly on the effectiveness of the service providers' negotiations. [25-26] In a study conducted in Turkey, Gurcanli et al. stated that staff participation in making decisions to purchase medical equipment is completely technicalbased. Employee participation rates can vary from nonparticipation (where supervisors make all purchasing decisions) to full participation (where anyone can participate in the decision-making process). [39] Amerion et al. stated that medical equipment should be purchased after consultation with all staff and specialist members and with the majority of votes. [29]
Regarding governmental aids and interventions, Salehi et al. suggested that if the government increased the purchasing power of medical centres by providing loans and facilities, these centres could be more willing to support purchases of their necessary medical equipment. [40] Chakravaddi et al. stated that in India, the most expensive and modern medical equipment is purchased through loans obtained from the World Bank. [41] Chakravaddi et al. imply that in recent years, India's private sector invested heavily in the purchase of medical equipment by participating in equipment management [38]. In their research, Boyer and Lio stated that in China, medical equipment is procured from the state budget. $[27,42]$

Concerning the control aspect, many governments have passed national policies and laws for the production, distribution, purchase and maintenance of medical equipment to ensure the effectiveness, safety, and rational use of these devices. [43] Dolan et al. stated that in the United States, agencies such as the US Food and Drug Administration and the European Union's Medical Device Directive have made stricter laws to control and enforce appropriate medical devices for humans. In Canadian hospitals, the technical standards of medical equipment, which are international standards, are regularly updated by national and local organizations in this country. [44]

Chen et al. in their study stated that the Chinese government has begun to formulate and apply laws and policies in this field since 2006. [45] Oner et al. stated that drug and medical equipment regulations in Turkey are formulated in association with the Insurance Fund of Social Security Institute and the Drug and Medical Devices Administration; some of the laws approved in the EU have also been applied in this country. [46] Nevertheless, Tiryakioglu et al. stated that unclear purchase rules, unawareness of organizational strategies, shortage of communications amongst users, lack of organizational knowledge about potential capabilities of suppliers, and lack of purchasing skills are factors leading to purchase management deficiencies in Turkey. [47] In their research, Potel \& Chakravaddi stated there are a few standards and regulations in India for the production, import and sale of medical equipment. Currently, medical equipment in this country is considered a part of drug laws and its regulations are approved accordingly. [41, 48]

In terms of organization, respondents paid more attention to the legal requirement of new building constructions, 
hospital ward developments, compilation of its plans with regards to concerns about up-to-date equipment and the creation of new wards in health centres, all of which are aimed for the patients' well-being. In their research, Tiryakioglu et al. stated that the National Health Transformation Initiative and the Import Dependency Reduction Program have assisted Turkey's hospitals and enabled them to expand to thousand-bed hospitals, which can result in higher costs. [47] Also, Chakravaddi et al. stated that the Indian Government also pays particular attention to the modernization of its health centres and the purchase of medical equipment; it employs experts in these fields so as to improve decision-making tasks and processes. [41]

As The findings of the present study showed, several components affect the purchase management of medical equipment, which their determination and review, as well as the integration and summarization of the results, make purchase management a specialized and sometimes complex matter. Insufficient attention to the issues raised in this field due to the limited level of information and expertise or one-dimensional perspective has led to an inappropriate summary of data, which causes decisionmaking to be made incorrectly.

Despite pressure from physicians and patients to use new and expensive technologies and equipment that have not been proven effective; healthcare centres must have appropriate plans and make the right decisions in buying efficient medical equipment. Therefore, attention must be paid to scientific advancements and consequently medical equipment in order to meet the needs of stakeholders and the specific and non-specific hospital revenues in medical equipment purchase management.

Price realization, playability, bargaining power and proper, and sufficient after-sales services are prerequisites of efficient purchase management, especially in Iran where exchange rate fluctuations, sanctions, and economic pressures are more evident.

Up-to-date equipment and the use of new methods of purchase in medical centres that are all for the well-being of patients and increasing the service of the hospital; need efficient supply process equipment under the close supervision of managers hospita.

This can be done by bargaining with managers appropriate procurement contracts and communication with NGOs receive government assistance, develop guidelines and clinical guidelines and make them available to all providers service, guaranteeing the development of a comprehensive educational, cultural, and bedding package to raise the level of awareness of people and service providers, align by forming treatment economics working groups to justify and sensitize practical clinical groups.

\section{ACKNOWLEDGMENT:}

The authors thank all staff members and managers of the hospitals affiliated with the Tehran University of Medical Sciences who supported and contributed to this research.

\section{CONFLICT OF INTEREST:}

The authors had no conflict of interest in the various stages of this research.

\section{References:}

1. Iadanza E, Gonnelli V, Satta F, Gherardelli M. Evidence-based medical equipment management: a convenient implementation. Medical \& Biological Engineering \& Computing. 2019;57: 2215-2230.

2. Lee M, Yoon Y, Ryu G, Sook Bok H, Yoon K, Park S, Lee K. Innovative Distribution Priorities for the Medical Devices Industry in the Fourth Industrial Revolution. Int Neurourol J. 2018;22(2): 83-90.

3. Tourani S, Chegini Z, Mosadeghrad A. Prioritizing Factors Influencing Purchase of Medical Equipment in Selected Hospitals in Tehran Using Analytic Hierarchy Process Model. Journal of Health Administration. 2015; 59(18): 55-65.

4. Shamayleh A, Awad M, Farhat J. IoT Based Predictive Maintenance Management of Medical Equipment. Journal of Medical Systems. 2020; 44: 72.

5. Stewart R. Getting the most of your mobile assets. http:// healthcare.flexity.ca/healthcare-itblog/2012/6/25/getting-the most- of-your-mobileassets.html Accessed 18 October 2019.

6. Abele J. Administration of medical electronics: A review of some criteria basic to effective and economical management of medical. Biomedical Instrumentation \& Technology .2017: 53-56.

7. Malmir B, Dehghani S, Firouzi Jahantigh F, Najjartabar M. A New Model for Supply Chain Quality 
Management of Hospital Medical Equipment through Game Theory . 6th International Conference on Information Systems, Logistics and Supply Chain ILS Conferen. 2016: 1-9.

8. Ivelve I, Kneppo P, Bartak M. Multicriteria decision analysis: A multifaceted approach to medical equipment management.Technological and Economic Development of Economy.2014: 576-589.

9. Klasaa K, Greer S, Ginneken E. Strategic Purchasing in Practice: Comparing Ten European Countries. Health Policy. 2018; 122: 457-472.

10. Bäckstranda J, Suurmondb R, Raaijc E, Chen C. Purchasing process models: Inspiration for teaching purchasing and supply management. Journal of Purchasing and Supply Management. 2019; 25.

11. Celiz R, Cruz Y, Sanchez D. Cloud Model for Purchase Management in Health Sector of Peru based on loT and Blockchain. IEEE. 2018.

12. Callea G, Armenl P, Marsilio M, Jommi C. The impact of HTA and procurement practices on the selection and prices of medical devices. Social Science \& Medicine. 2017; 174: 89-95.

13. Ivelve I, Kneppo P, Bartak M. Method for selecting expert groups and determining the importance of experts' judgments for the purpose of managerial decision-making tasks in health system. $E$ \& $M$ Ekonomie a Management. 2015;18(2): 57-72.

14. Barasa E, Molyneux S, English M, Cleary S. Hospitals as Complex adaptive systems: A case study of factors influencing priority setting practices at the hospital level in Kenya. Social Science \& Medicine. 2017; 174: 104-112.

15. Tomas B, Consoli A. Whatever works: Uncertainty and technological hybrids in medical innovation. Technological Forecasting and Social Change. 2012; $79(5)$ : 932-948.

16. Ratel V, Grutters J, Harten W, Joore M. Value of research and value of development in early assessments of newmedical technologies. Value in Health. 2013;5(16): 720-728.

17. Wernz C, Gehrke I, Ball D. Managerial decision-making in hospitals with real options analysis. Inf Syst E-Bus Manage. 2015; 13: 673-691.

18. Mazloum Vajari S, Masoudi Asl I, Hajinabi K, Riahi L. Medical Equipment Replacement Planning Using the SWOT-ANP-WASPAS Hybrid Approach .Journal of healthcare management. 2019; 2(10):91-107.
19. Gerandi G. Whether something cool is good enough": The role of evidence, sales representatives and nurses' expertise in hospital purchasing decisions. Social Science \& Medicine. 2016; 165: 82-91.

20. Wang Y. Discussion on the reliability of the quality management of medical devices. Zhongguo Yiliao Oixie Zazhi. 2012; 4(36): 300-301.

21. Auntony A, Yang C. An overview of ISO9000 application to drug, medical device, and environmental management issues. Food \& Drug L.J. $1994 ; 49$.

22. Bagheri R, Mazaheri M, Fadaie M. Management of purchases and supplies of goods in the organization. Support services management of Isfahan University of Medical Sciences.2015.

23. Bandalos DL, Finney SJ. Item Parceling Issues in Structural Equation Modeling. New Developments and Techniques in Structrul Equation Modeling .2001, 263:296

24. Habibie A \& Adan Var M. Structural equation modeling and factor analysis. Academic Center for Education, Culture and Research (ACECR). 2017.

25. Liyanto A, Wijaya Ch, Leonita K. Dominant Factor Analysis of Medical Equipment and Device Affect Against Customers' Repeat Purchase Decision. Indian Journal of Public Health Research \& Development, February. 2020;11 (2).

26. Preker A, Langenbrunner J, Belli P. Public Ends Private Means Stategic Purchasing of Health Services. The World Bank Washington DC .2007.

27. Boyer F, Morshed B, Mussivand A. Thoughts and Progress. Artificial Organs.2015; 39(6): 520-540.

28. Balarajan V, Selvaraj A, Subramanian A. India: Towards Universal Health Coverage 4 Health care and equity in India. Series. $2011 ; 377$.

29. Amerion A, Alijanzadeh M, Teymourzadeh E. Effective factors on the management of medical equipment maintenance in a military hospital: A qualitative study in Iran. EBNESINA- Journal of Medical. $2015 ; 3(17)$ : 11 18.

30. Saleh N, Petti A, Abdel Wahed M, Shrawi A. A Conceptual Priority Index for Purchasing Medical Equipment in Hospitals. Journal of Clinical Engineering. 2015; 40.

31. Alfaghadeh A, Jafari Pouyan A, Omidi Morad A. Medical Equipment Manegement in Developing Countries. Hospital. 2015: 23-27. 
32. 32. Obremskey W, Dail T, Jahangir A. Value-based purchasing of medical devices. J Clin Orthop Relate Res. 2012: 1054-1064.

33. Pauli M, Burns L. Price Transparency for Medical Devices. Health Affairs. 2008; 6( 27).

34. Overview of Medical Device Industry Healthcare Statistics. Cairo, Cairo, Egypt. 2018.

35. Ozmir A, Olgan C. Regulation of Medical Devices in Turkey. Medtronic. 2016.

36. Ozmir Z, Can A, Ordu A. Medical device reimbursement pricing rules in Turkey: with past and current practices, Looking forward .Medtronic. 2016.

37. Kumar C, Chen C, Chadheri M, Ganjou Sh, Mahajan $V$, Sinha A, Sen A.India: Towards Universal Health Coverage 6 Financing health care for all: challenges and opportunities. Series. $2011 ; 377$.

38. Chakravaddi, A. Medical Technology in India: Tracing Policy Approaches. Centre of Social Medicine and Community Health, New Delhi, India. 2018.

39. Gurcanli J, Baradan A, Uzun A. risk perception of construction equipment operators on construction sites of turkey. International journal of industrial Ergonomics. 2015; 46: 59-68.

40. Salehi M.KH, Danesh Parvar H.R, Rezaie N. Forensic examination of injuries caused by medical equipment. Quarterly Medical Law. 2013; 27( 7): 161-193.

41. Chakravaddi A. Medical Equipment Industry in India: Production, Procurement and Utilization. Indian Journal of Public Health. 2013; 57(4): 203-207.

42. Lio D, Darimonet B. Health care system of the People's Republic of China: The boundary between privatization and public health services. Germany, Wuhan University. 2013.

43. Enemark E, Alban A, Vazquez A. Purchasing Pharmaceuticals. HNP Discussion Paper, World Bank, Washington DC. 2004.

44. Dolan AA. Clinical Engineering Overview. Canada: MCgROW. 2003.

45. Chen $Y$, Yin Z, Xie O. suggestion to ameliorate the inequity in urben/ rural allocation of healthcare resources in china. International journal for equity in health. 2014; 34(13).

46. Oner $G$, Keclk M. Turkish medicines and medical devices agency. Geneva: who, who technical briefing seminar. 2014.
47. Tiryakioglu M, Yolek M. Development-based public procurement policies: a selective survey of literature, cross-country policy experience and the Turkish experience. The European Journal of Social Science Research. 2015; 28(3): 344-359.

48. Potel V, Parikh R, Nanranj C. Assuring health coverage for all in India. Seris . 2015; 386. 
TABLE 3: REGRESSION COEFFICIENTS IN STANDARD MODE

\begin{tabular}{|c|c|c|c|c|c|c|c|}
\hline $\begin{array}{l}\text { PATH } \\
\text { COEFFICIENT }\end{array}$ & P-VALUE & $\begin{array}{l}\text { CRITICAL } \\
\text { RATE }\end{array}$ & $\begin{array}{l}\text { STANDARD } \\
\text { ERROR }\end{array}$ & ESTIMATE & $\begin{array}{l}\text { HIDDEN } \\
\text { VARIABLE }\end{array}$ & PATH & QUESTION \\
\hline 1.238 & 0.019 & 2.769 & 0.587 & 1.389 & Management & $<--$ & Planning \\
\hline 1.244 & --- & --- & --- & 1 & Management & $<--$ & Decision \\
\hline 0.845 & 0.014 & 2.447 & 0.536 & 1.312 & Management & $<--$ & Organization \\
\hline 1.151 & 0.017 & 2.378 & 0.567 & 1.349 & Management & $<---$ & Leadership \\
\hline 0.973 & 0.008 & 2.647 & 0.529 & 1.099 & Management & $<--$ & Control \\
\hline 0.149 & 0.052 & 1.943 & 0.254 & 0.493 & Planning & $<--$ & S3 \\
\hline 0.258 & 0.003 & 2.941 & 0.256 & 0.752 & Planning & $<--$ & S4 \\
\hline 0.285 & 0.006 & 2.726 & 0.233 & 0.636 & Planning & $<---$ & S5 \\
\hline 0.294 & 0.001 & 3.187 & 0.291 & 0.926 & Planning & $<--$ & S6 \\
\hline 0.153 & 0.048 & 1.979 & 0.254 & 0.503 & Planning & $<--$ & 58 \\
\hline 0.296 & --- & --- & --- & 1 & Planning & $<--$ & S9 \\
\hline 0.228 & 0.031 & 2.013 & 0.38 & 1.3 & Planning & $<--$ & S10 \\
\hline 0.368 & --- & --- & --- & 1 & Decision & $<--$ & S11 \\
\hline 0.162 & 0.042 & 2.035 & 0.424 & 0.862 & Decision & $<--$ & S13 \\
\hline 0.254 & 0.011 & 2.558 & 0.275 & 0.704 & Decision & $<--$ & S14 \\
\hline 0.325 & 0.002 & 2.058 & 0.36 & 1.1 & Decision & $<--$ & S15 \\
\hline 0.187 & 0.027 & 2.21 & 0.463 & 1.023 & Decision & $<--$ & S16 \\
\hline 0.218 & 0.017 & 2.387 & 0.539 & 1.287 & Decision & $<--$ & S17 \\
\hline 0.168 & 0.038 & 2.076 & 0.393 & 0.817 & Decision & $<--$ & S18 \\
\hline 0.215 & 0.009 & 2.611 & 0.41 & 1.069 & Organizing & $<--$ & S20 \\
\hline 0.22 & 0.016 & 2.4 & 0.436 & 1.046 & Organizing & $<--$ & S22 \\
\hline 0.269 & --- & -- & --- & 1 & Organizing & $<--$ & S23 \\
\hline 0.213 & 0.012 & 2.52 & 0.337 & 0.848 & Organizing & $<--$ & S24 \\
\hline 0.259 & 0.004 & 2.915 & 0.383 & 1.118 & Organizing & $<--$ & S25 \\
\hline 0.218 & 0.01 & 2.573 & 0.369 & 0.95 & Leadership & $<--$ & S26 \\
\hline 0.328 & --- & --- & --- & 1 & Leadership & $<--$ & S28 \\
\hline 0.311 & 0.003 & 2.995 & 0.494 & 1.479 & Leadership & $<--$ & S29 \\
\hline 0.198 & 0.003 & 2.972 & 0.366 & 1.087 & Leadership & $<--$ & S30 \\
\hline
\end{tabular}




\begin{tabular}{|c|c|c|c|c|c|c|c|}
\hline 0.302 & 0.003 & 2.535 & 0.426 & 1.325 & Leadership & $<---$ & S31 \\
\hline 0.202 & 0.021 & 2.3 & 0.453 & 1.041 & Leadership & $<--$ & S32 \\
\hline 0.301 & 0.004 & 2.346 & 0.584 & 1.256 & Control & $<--$ & S33 \\
\hline 0.211 & 0.003 & 2.365 & 0.45 & 0.925 & Control & $<--$ & S34 \\
\hline 0.287 & 0.012 & 2.505 & 0.287 & 0.719 & Control & $<--$ & S35 \\
\hline 0.268 & 0.003 & 2.914 & 0.469 & 1.125 & Control & $<--$ & S36 \\
\hline 0.298 & 0.004 & 2.854 & 0.327 & 0.879 & Control & $<--$ & S37 \\
\hline 0.305 & --- & --- & --- & 1 & Control & $<--$ & S38 \\
\hline
\end{tabular}

